\title{
The Dyeing Process and the Environment: Enhanced Dye Fixation on Cellulosic Fabric Using Newly Synthesized Reactive Dye
}

\author{
Umme Habibah Siddiqua ${ }^{1 *}$, Shaukat Ali ${ }^{1}$, Tanveer Hussain ${ }^{2}$, \\ Haq Nawaz Bhatti ${ }^{1}$, Muhammad Asghar ${ }^{3}$ \\ ${ }^{1}$ Department of Chemistry, University of Agriculture, Faisalabad, Pakistan \\ ${ }^{2}$ Department of Textile Processing, National Textile University, Faisalabad, Pakistan \\ ${ }^{3}$ Department of Biochemistry, University of Agriculture, Faisalabad, Pakistan
}

Received: 2 December 2016

Accepted: 11 January 2017

\begin{abstract}
New types of dyestuff moieties are being introduced to get the ease in imparting color to various substrates and sorting out the ways to improve the quality of dyed fabric using environmentally friendly techniques. To contribute to this research effort, the present study was carried for dyeing cellulosic fabric using novel bi-functional reactive dye. The synthesized dye contained sulphatovinylsulfone and monochlorotriazine functionality. The important influencing parameters for the exhaust method, e.g., dyeing temperature, concentration of salt, and alkali were optimized and their interaction was studied using central composite design. The results indicated that $61.5^{\circ} \mathrm{C}$ was found to be suitable for the maximum exhaustion and fixation of the dye on cotton fabric. The optimum concentration of salt $(30.01 \mathrm{~g} / \mathrm{L})$ and alkali $(22.32 \mathrm{~g} / \mathrm{L})$ for dye experimentally resulted in $84.98( \pm 3) \%$ of exhaustion and $79.00( \pm 3) \%$ fixation on cellulose fabric. Fastness properties were good-to-excellent for the novel reactive dye applied on cotton fabric. A comparison of the results with the commercial reactive dye showed that attained results were within a practical range suitable for commercial dyeing.
\end{abstract}

Keywords: cotton dyeing, fastness, optimization, central composite design

\section{Introduction}

During the manufacturing and processing of dyes, color and chemical discharge from the dyeing industry is a major threat to the environment [1-2]. These discharged colored effluents contaminate natural water bodies due to their toxic effects. Although they bring color to our lives, dyes are responsible for environmental pollution

*e-mail: u.habibah5@gmail.com
[3-4]. Dyes that originate from textile industries are carcinogenic and toxic in nature and pose a major threat to the surrounding ecosystem [5]. Dye effluent contains numerous organic pollutants that are poisonous and harmful to human beings. Recent research has shown that approximately $12 \%$ of dyes are wasted per year during the manufacturing process.

But dyes are far and wide in our lives and make the world beautiful. They have been used in the textile industry to change the functionality and appearance of materials 
since their inception. Particularly, specific functional, visual, and mechanical properties of the textiles have been achieved by using dyes. Reactive dyes are the most popular for dyeing cellulosic fibers because of their outstanding characteristics, e.g., excellent wet fastness properties, a wide variety of shades, and simplicity in their application methods [6].

Dyeing is a practice of imparting colors to a textile matrix. It involves dye application in a homogeneous manner to the substrate to attain level dye shade and desirable fastness properties. At different stages of dyeing alkali and inorganic electrolytes are added to the dyebath. Depending on the method of dyeing, intensity of color, and composition of the used dyes, the amount of added electrolytes vary between 50 and $100 \mathrm{~g}$ [7]. Any deviation in these variables can directly affect the color fastness of the dyed fabric, and dyeing processes constantly produce a huge amount of wastewater of diverse composition, frequently containing salt, urea, metal ions, and dye, which is uneconomical and harmful to plant and animal life [8-9]. Additionally, removal of salts by water treatment requires a significant amount of energy, time, and cost [10-11].

A classical method of process optimization by varying one factor at a time (OFAT) while keeping all other factors constant at a specified level cannot investigate the interactive effect of all the involved factors. It also requires a large number of time-consuming experiments for determining optimum conditions [12]. These drawbacks of a classical study can be eradicated by using response surface methodology (RSM), which is a statistical experimental design. RSM is a compilation of statistical and mathematical procedures useful for developing, optimizing, and improving the processes and even in the presence of multifarious interactions, relative significance of various affecting variables can be calculated [1314]. Moreover the optimization process increased the exhaustion of the dye on the substrate, which decreases environmental pollution by reducing the amount of dye and chemicals in the wastewater [15-18].

The current study focused on optimizing the dyeing variables for novel reactive dye. The objective was to achieve better exhaustion and fixation, which in turn reduced dye wastage and environmental pollution.

\section{Material and Methods}

The present research work was carried out in the Processing Department of National Textile University, Faisalabad. A pre-treated cotton fabric was used throughout the research work. The UV visible absorption spectra were measured using a Perkin Elmer (CE-7200) spectrophotometer. An HT dyeing machine (model HD$12 \mathrm{E})$ was used for dyeing the cotton fabric.

\section{Dye Synthesis}

New azo reactive dye with heterofunctional reactive groups in the structure was synthesized at the
Department of Chemistry, University of Agriculture, Faisalabad. The dye was synthesized by following a general scheme of synthetic steps comprised of condensation, diazotization, and coupling reactions [19]. Fig. 1 showed the scheme for dye synthesis having reaction conditions.

\section{Dyeing Procedure}

All dyeing with the novel heterobifunctional (MCT/SES) reactive dye was carried out in stainless steel dye pots housed in a lab-scale exhaust dyeing machine, using $2 \%$ dye shade and a dye liquor-to-fabric ratio of 25:1. Dye solutions were made in distilled water. $\mathrm{Na}_{2} \mathrm{SO}_{4}$ was used as an electrolyte and $\mathrm{Na}_{2} \mathrm{CO}_{3}$ was used as alkali in the exhaust dyeing [20]. After dyeing, the unfixed dye was removed from the cotton fabric by soaping with $2 \mathrm{~g} / \mathrm{L}$ Perlavin PAM (non-ionic) detergent at the boil for $15 \mathrm{~min}$., followed by rinsing with hot water, cold water, and drying. After dyeing, the color strength (percentage) of the dyed cotton samples was evaluated for dyed samples using a spectraflash spectrophotometer.

\section{Optimizing Dyeing Parameters Using Central Composite Design}

In the present work optimization of different dyeing parameters for the new reactive dyes was carried out through response surface methodology. Central composite design (CCD) was used for the experimental work and three independent influencing variables were selected as dyeing temperature (A), salt (g/L) (B), and alkali (g/L) (C). The ranges selected for three independent variables were $45-75^{\circ} \mathrm{C}$ for temperature, $20-60 \mathrm{~g} / \mathrm{L}$ for salt, and $15-45 \mathrm{~g} / \mathrm{L}$ for alkali. A total of 20 runs of experiments by Design Expert software (version 7.0.0) were generated (Table 2). A three-factor central composite design used in this study consisted of six axial points, six central points, and eight factorial points. Experimental error and reproducibility of the data obtained are checked with the help of central points of central composite design.

\section{Color Fastness Testing}

Fastness testing of the dyed samples was carried out according to ISO standard methods [21]:

- Color fastness to rubbing was determined according to ISO 105-X12 (1987).

- Color fastness to light (xenon arc) was determined according to ISO 105-B02 (1988).

- Color fastness to washing was determined according to ISO 105-C02 (1989).

- Color fastness to chlorinated water was determined according to ISO 105-E03.

- Color fastness to perspiration was determined according to ISO 105-E04 (1989). 


\section{Results and Discussion}

Characterization of the Synthesized Dye

$\mathrm{UV} /$ visible absorption spectra of synthesized dye was recorded in the wavelength range of 200-800 $\mathrm{nm}$ using distilled water. The absorption maxima wavelength $\left(\lambda_{\max }\right)$ appeared in the visible region of spectrum. Synthesized dye had maximum absorption $\left(\lambda_{\text {max }}\right)$ at $475 \mathrm{~nm}$.

Fourier transform infrared spectroscopic (FTIR) analysis was carried out using a Perkin Elmer spectrophotometer in the mid-infrared region of $400-4,000 \mathrm{~cm}^{-1}$. Characteristic peaks appearing in a particular region of the spectrum of the dye (Fig. 2a)<smiles>Nc1ccc(S(=O)(=O)OCCOS(=O)(=O)O[Na])cc1</smiles><smiles>Nc1cc(S(=O)(=O)O)cc2cc(S(=O)(=O)O)cc(O)c12</smiles>

(1) Final Condensed Product

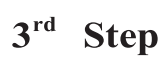

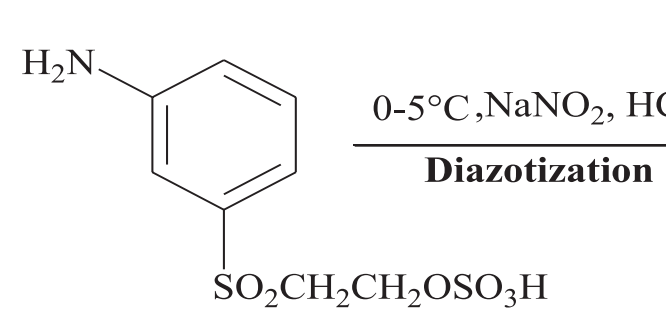

Meta ester<smiles></smiles>

Diazotized product

Coupling with (1)

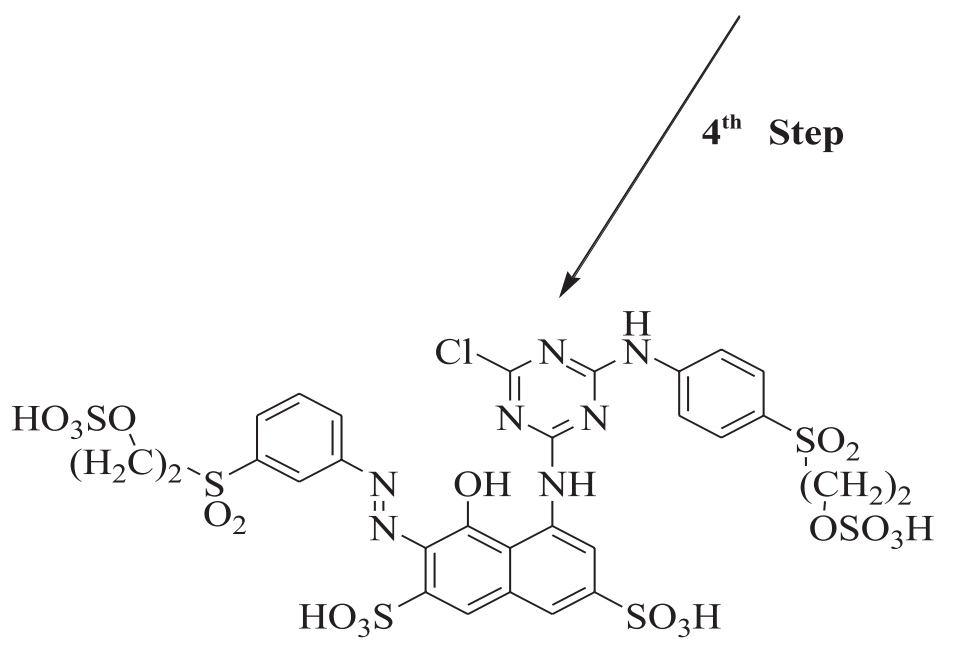

Synthesized Dye

Fig. 1. Synthesis scheme of azo reactive dye. 

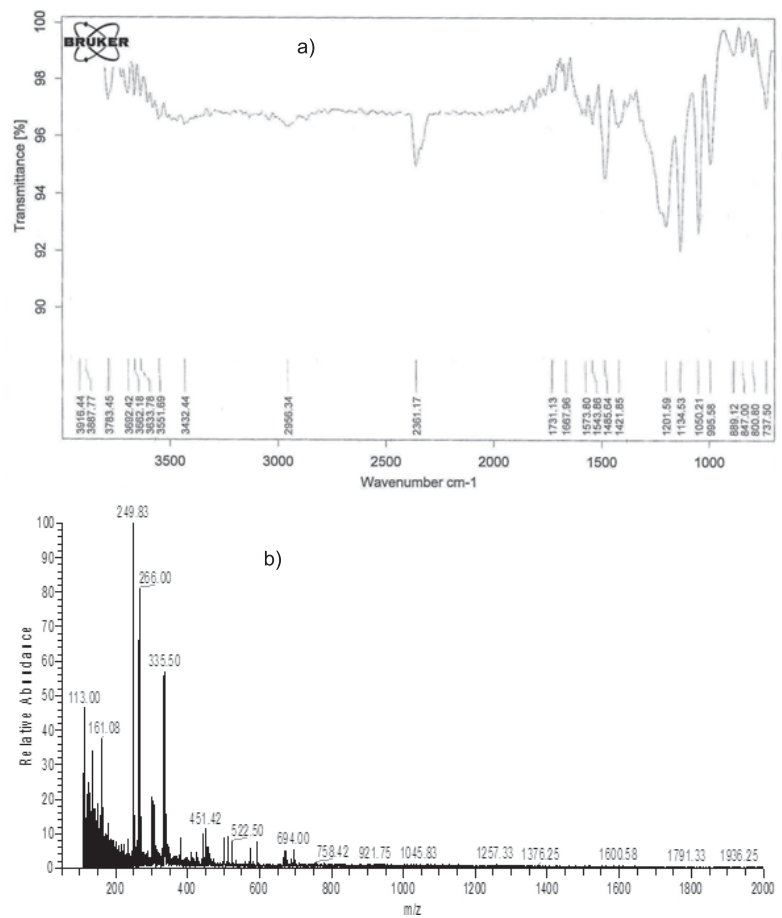

Fig. 2. a) FT-IR spectrum and b) ESI-MS spectrum of the novel reactive dye.

were due to the presence of the different functional groups. FT-IR spectroscopic analysis for dye demonstrated that a characteristic peak at stretching frequency of $3,432.44 \mathrm{~cm}^{-1}$ was due to the $\mathrm{NH}$ functional group. Another band that appeared at $1,573.80 \mathrm{~cm}^{-1}$ was due to the azo $(\mathrm{N}=\mathrm{N})$ functional group stretching vibration. Strong and intense bands appearing in the 1,201-1,134 $\mathrm{cm}^{-1}$ and $1,050.21 \mathrm{~cm}^{-1}$ region were due to the stretching vibrations of the $\mathrm{SO}_{3}$ and $\mathrm{S}=\mathrm{O}$ groups, respectively. Characteristic peaks in the 737.50 and $995.58 \mathrm{~cm}^{-1}$ regions were because of the substituted benzene rings present in the structure of synthesized dye.

The structures of the synthesized novel reactive azo dyes were ultimately confirmed and authenticated by determining their molecular weights through mass spectrometry. The electrospray ionization method was used for the analysis of polar high molecular weight compounds synthesized in this study. The background noise in the ESI-MS spectra (Fig. 2b) can be explained by the presence of impurities and high level of salts in the synthesized dyes. The molecular weight of the synthesized dye was $1,090.86$ with molecular formula $\mathrm{C}_{29} \mathrm{H}_{22} \mathrm{~N}_{7} \mathrm{O}_{19} \mathrm{~S}_{6} \mathrm{ClNa}_{4}$. The signal corresponding to $\mathrm{m} / \mathrm{z}=249.83$ was observed in the spectrum for novel reactive dye.

\section{Dyeing Properties of the Synthesized Dye}

The effect of temperature (A), salt (B), and alkali (C) and their interactions each at five levels on the exhaustion and fixation of the novel reactive dye was investigated. The results were evaluated by analysis of variance
(ANOVA). For evaluating the fitted model quality ANOVA application was found to be the most reliable method [22]. Variation due to treatment (variable levels combination change) was compared with variation due to random error of the generated responses by using ANOVA. Linear, interaction effects, coefficient of quadratic, and p-values for the exhaustion and fixation of both novel reactive dyes were obtained through ANOVA. Prob $>$ F value less than 0.05 for the models indicates statistically significant model terms. All interactions were found to be almost significant. For the validity of the developed model the lack of fit values should be non-significant [23].

\section{Fitness of the Quadratic Model}

Close agreement between actual and predicted exhaustion and fixation values was observed for the azo reactive dye by applying the pretreated cotton fabric. Fig. 3 represented the actual and predicted exhaustion (A) and fixation (B) (\%) values for the synthesized azo reactive dye. These results indicate good fitness of the model to the response data.

\section{The Individual Effect of Dyeing Parameters}

The individual effect of qualitative variables such as temperature (A), salt (B), and alkali (C) was found by perturbation plots. Fig. 3 showed the perturbation plots for exhaustion and fixation. A perturbation plot does not depict the interaction effect and represents the one factor experimentation at a time. The effect of all the variables in the design space at a particular point can be compared with the help of a perturbation plot. The response is plotted by keeping all the variables constant while changing only one variable over its range. A steep slope or twist in a variable shows sensitivity of the response to that factor while a relatively straight line presents insensitivity to change in that particular variable [24]. Fig. 3c) shows that it is clear that salt has a marked effect on the exhaustion of the dye, while alkali has a pronounced effect on the fixation of the dye as compared to other factors (Fig. 3d).

\section{Effect of Dyeing Variables on Dye Exhaustion and Fixation}

The three-dimensional surface graphs between the factors for interaction study are presented in Fig. 4. These graphs are plotted as a function of two variables at a time by maintaining the third factor constant at its central point. Graphs indicated that a significant interaction existed between every two variables, and surface restricted between the smallest ellipses in the contour diagrams specifies the maximum yield.

The interaction between temperature and salt concentration was studied by varying the temperature from $30-90^{\circ} \mathrm{C}$ and salt concentration varied from $0-80 \mathrm{~g} / \mathrm{L}$. Results were obtained in the form of 3-D surfaces in Fig. 4a). Graphs illustrated that the increase 

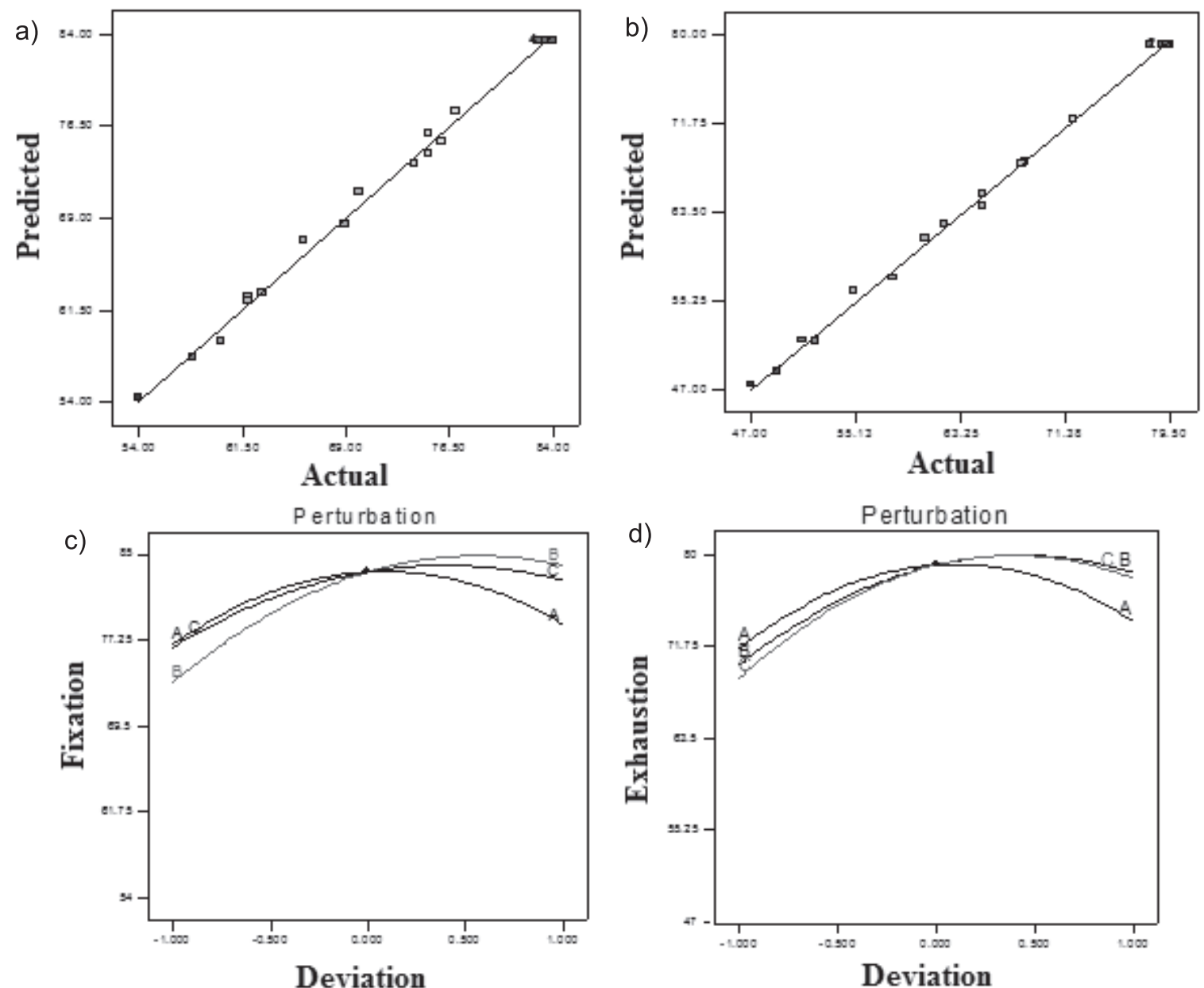

Fig. 3. The actual and predicted values for the exhaustion a) and fixation b) response and overlay perturbation plot of all the independent variables for exhaustion c) and fixation d) of reactive dye.

in temperature and salt concentration increased the exhaustion and fixation percentage of the dye, which showed the positive interaction and synergistic effect of both factors on the exhaustion and fixation responses. It was clear from graphs that increases in the amount of salt up to optimum concentration increased the exhaustion and fixation percentages of novel dye because salt reduces the electrostatic anion-anion repulsion between cellulose and dye molecules, which increases the exhaustion and fixation of the dye on substrate. However, at an optimum level of salt, an increase in temperature resulted in an increase in exhaustion and fixation percentage up to $61.5^{\circ} \mathrm{C}$ due to the increased transfer of dye on the fabric and thereafter a decrease in exhaustion and fixation was observed down to $75^{\circ} \mathrm{C}$ due to dye hydrolysis at high temperature. Dyeing using salt lower or higher than the optimum value may cause uneven dyeing and poor color strength due to dye aggregation and low migration rate. Farha et al. [25] envisaged that exhaust dyeing of cotton fabric with reactive dyes requires the presence of salt (sodium sulphate), which promotes dye exhaustion by suppressing the negative charge at the surface of fiber.

The results for the combined effect of alkali and temperature are presented in Fig. 4b). There was significant effect of alkali and temperature on the exhaustion and fixation of the new reactive dyes. It was clear from Fig. 4b) that exhaustion of dye increased by adding alkali and increasing temperature up to a certain limit. At $61.5^{\circ} \mathrm{C}$ and alkali concentration of $22.32 \mathrm{~g} / \mathrm{L}$ maximum exhaustion and fixation percentages were obtained for newly synthesized reactive dye because appropriate $\mathrm{pH}$ was necessary in the case of sulphatoethylsulphone reactive dyes to convert them into the active form vinylsulphone by the addition reaction and also for the activation of cotton material. At higher and lower than these values both responses decreased because at a higher level dye hydrolysis increased while at a lower level of alkali, fabric pores are not in exact orientation into the interior for covalent fixation of the dye molecules [26]. Fig. 4b) showed positive interaction and a significant effect of alkali and temperature on the dyeing responses.

The interaction of salt and alkali on the exhaustion and fixation of the newly synthesized reactive dye was investigated and presented in Fig. 4c). The graphical data showed that at a maximum amount of salt (30.01 g/L) and minimum amount of alkali the exhaustion and fixation was not maximally obtained and both responses increased when alkali concentration was increased up to optimum 
concentration. This indicated a positive interaction and significant effect of both factors on the exhaustion and fixation of the novel dyes. At the minimum concentrations of both parameters the responses were minimum. Singla et al. [27] reported the use of sodium sulphate as an electrolyte to suppress the negative charge build-up at the fiber surface for dye uptake. The results obtained for
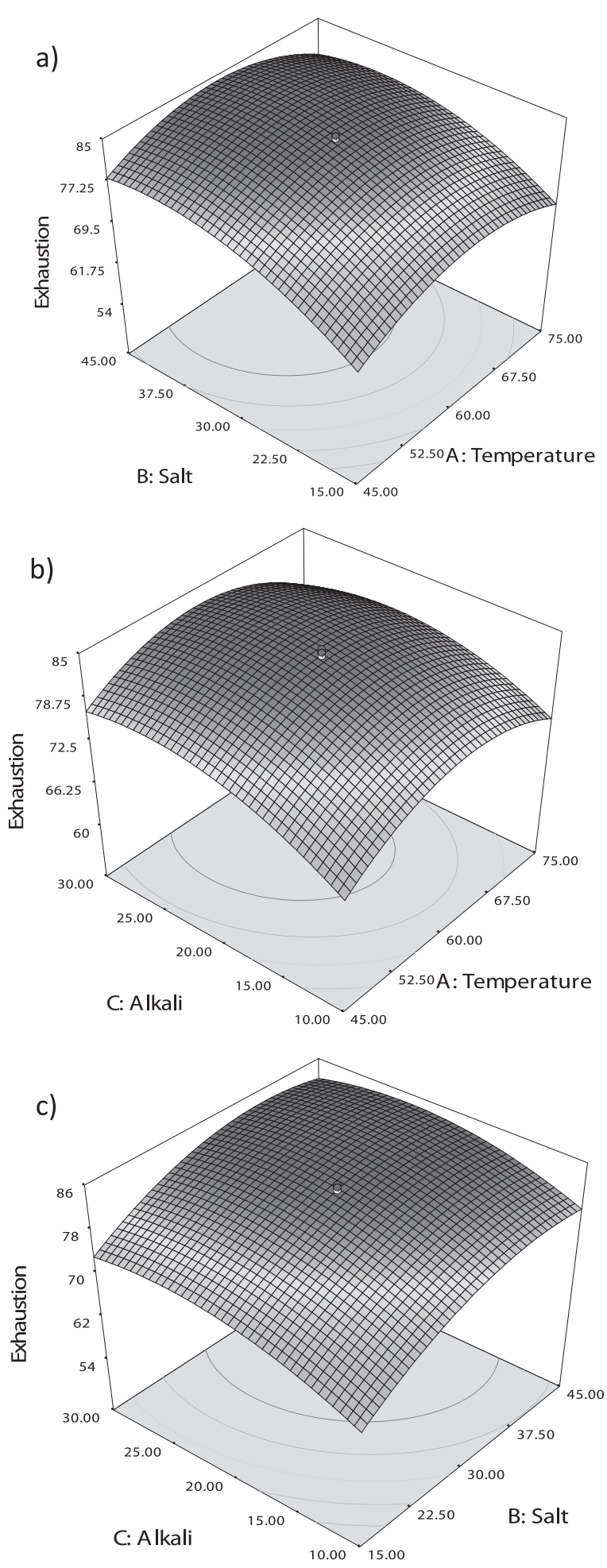

1.0 and $3.0 \%$ dye concentrations with $30-90 \%$ sodium chloride and $5-30 \%$ sodium carbonate. Based on these results, 43-44 g/L of sodium sulphate and 29-33 g/L of sodium carbonate were optimized for $2 \%$ shade of dyes 1 and 2, respectively.

Various optimized dyeing factors were determined by selecting numerical optimization. Values selected $\mathrm{f}$
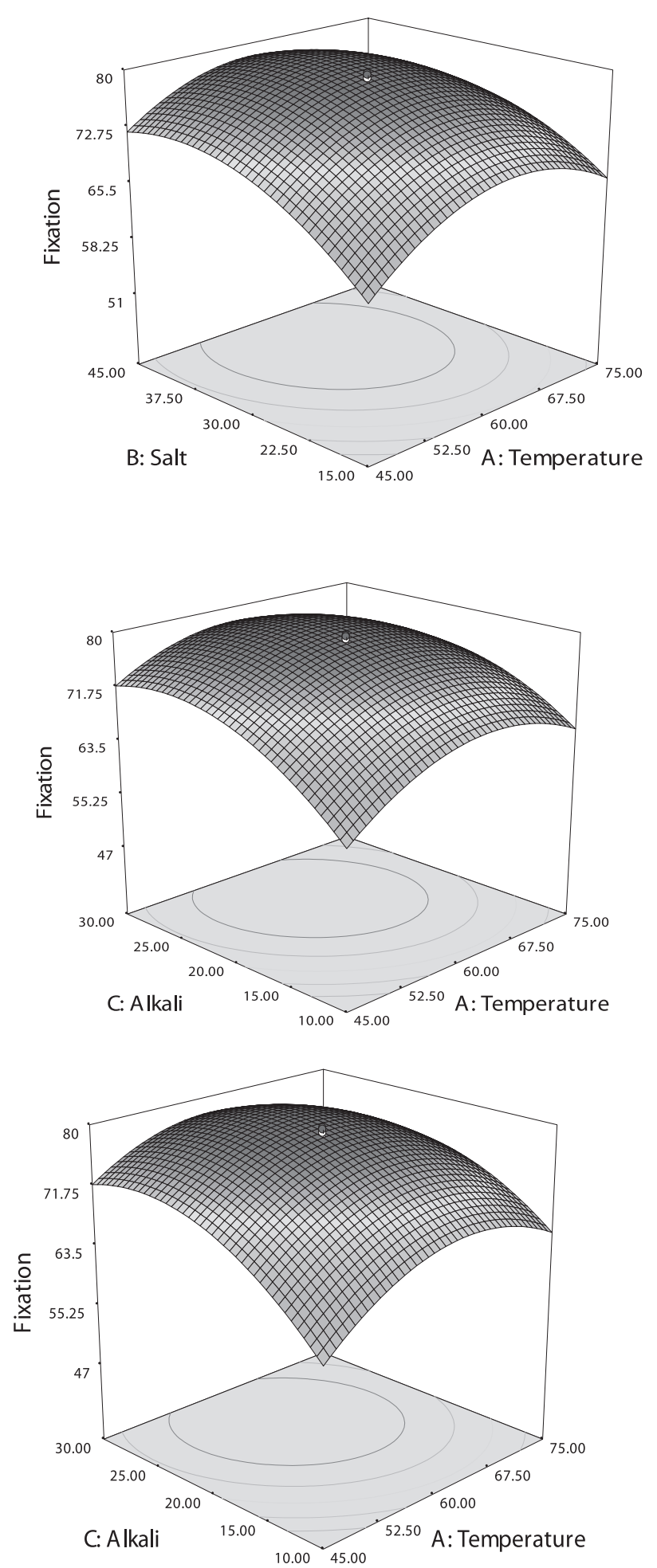

Fig. 4. 3D Response surface plots showing interactive effects of a) temperature and salt, b) temperature and alkali, and c) salt and alkali on the exhaustion and fixation of reactive dye. 
or dye were temperature $=61.5^{\circ} \mathrm{C}$, salt $=30.01 \mathrm{~g} / \mathrm{L}$, and alkali $=22.32 \mathrm{~g} / \mathrm{L}$, which experimentally resulted in $84.98( \pm 3) \%$ of exhaustion and 79 fixation percentage. The predicted values from the model were $89.6 \%$ and $83.2 \%$ for the dye exhaustion and fixation, respectively. Small errors between the experimental and predicted values indicated that values obtained through experimental studies are in good agreement with the predicted values from the model.

\section{Colorimetric Data}

The colorimetric data of the synthesized dye, i.e., L*, $a^{*}, b^{*}, C^{*}$, and $h^{*}$ were calculated for synthesized dye and compared with Reactive Red 195 commercial dye. The synthesized dye shade was comparable with Reactive Red 195 with K/S values of 22.40 and 17.40 for synthesized dye and Reactive Red 195, respectively. The $\mathrm{L}^{*}, \mathrm{a}^{*}, \mathrm{~b}^{*}$, $\mathrm{C}^{*}$, and $\mathrm{h}^{*}$ colorimetric data values were $32.74,51.19$, $2.80,53.27$, and 7.85 for synthesized dye, whereas these values were $41.28,53.57,1.19,53.79$, and 351.7 for Reactive Red 195. Data revealed that synthesized dye has a brighter shade (higher $\mathrm{C}^{*}$ value) and gave redder (higher $\mathrm{a}^{*}$ values) tone on cotton fabric than the standard dye (Reactive Red 195), making exhaust dyeing suitable for the reactive dye. Exhaustion of the dyes from the dye bath to fabric samples was good, and large amounts of dye were fixed to the fabric.

\section{Fastness Properties of the Synthesized Dye}

The results for color fastness of the synthesized dye and standard dye at $2 \%$ shade were recorded. Washing, rubbing, light, perspiration, and chlorinated fastness values for synthesized dye were $4,4,4,4-5$, and 3-4, whereas these values were 4, 4, 4, 4-5, and 4 for Reactive Red 195. Results indicate that washing, rubbing, light, perspiration, and chlorinated fastness properties of synthesized dye were comparable with Reactive Red 195. It was clear from the data that dye showed good-to-excellent fastness properties and comparable results with the standard commercial dye (Reactive Red 195), which may be attributed to the good penetration of the dye into the cotton fabric. Reactive dyes give good fastness properties on account of stable electron arrangement and covalent bond formation between the dye and fiber, which provide good resistance to washing and sunlight [27]. Therefore, in view of enhanced dye fixation and dyeing properties, the synthesized dye could possibly be used for dyeing of cotton fiber, which will be helpful in reducing dye wastage during the dyeing process to avoid contamination of the environment, since dye are toxic to living organisms [28-47].

\section{Conclusions}

Dyeing with reactive dyes on cotton fabric using the exhaust method requires high levels of control over a range of dyeing variables. The current study comprised the optimization of critical parameters like salt concentration, dyeing temperature, and concentration of alkali for dyeing cotton with novel reactive dye. The outcome of this study showed that maximum exhaustion (84\%) and fixation (79\%) take place for the newly synthesized bifunctional reactive dye with low salt and alkali concentration than the commercial reactive dye having $79 \%$ exhaustion and $72 \%$ fixation at optimized conditions. A comparison of the results with the commercially available Reactive Red 195 illustrated that the dye is commercially viable.

\section{Acknowledgements}

The authors are thankful to the Higher Education Commission (HEC) for financial support under the Ph.D. fellowship (Pin: 112-26780-2PS1-670).

\section{References}

1. KITKULNMCHAIY.,AJAVAKOMA.,SUKWATTASINITT M. Treatment of oxidized cellulose fabric with chitosan and its surface activity towards anionic reactive dyes. Cellulose, 15, 599, 2008.

2. FAKHRI A., ADAMI S. Adsorption and thermodynamic study of Cephalosporins antibiotics from aqueous solution onto $\mathrm{MgO}$ nanoparticles.J. Tai. Institu. Chemi. Eng. 45, 1001, 2014.

3. FAKHRIA., BEHROUZ S. Assessment of $\mathrm{SnS}_{2}$ nanoparticles properties for photocatalytic and antibacterial applications. Solar Energy. 117, 187, 2015.

4. FAKHRI A., KAHI D.S. Synthesis and characterization of $\mathrm{MnS}_{2} /$ reduced graphene oxide nanohybrids for with photocatalytic and antibacterial activity. J. Photochem. Photobio. B: Biol. 166, 259, 2017.

5. FAKHRI A., BEHROUZ S. Photocatalytic properties of tungsten trioxide $\left(\mathrm{WO}_{3}\right)$ nanoparticles for degradation of Lidocaine under visible and sunlight irradiation. Solar Energy. 112, 163, 2015.

6. FAKHRI A., NEJAD P.A. Antimicrobial, antioxidant and cytotoxic effect of Molybdenum trioxide nanoparticles and application of this for degradation of ketamine under different light illumination. J. Photochem.Photobio. B: Biol. 159, 211, 2016.

7. FAKHRI A., POURMAND M.,KHAKPOUR R., BEHROUZ S. Structural, optical, photoluminescence and antibacterial properties of copper-doped silver sulfide nanoparticles. J. Photochem.Photobio B: Biol. 149, 78, 2015.

8. ADAMCOV D., VAVERKOVA, M.D., STEJSKAL, B., BROUSKOVA, E. Household solid waste composition focusing on hazardous waste. Pol. J. Environ. Stud. 25, 487, 2016.

9. DARGAHI A., GOLESTANIFAR H., DARVISHI P., KARAMI A., HASAN S.H., POORMOHAMMADI A., BEHZADNIA A. An investigation and comparison of removing heavy metals (lead and chromium) from aqueous solutions using magnesium oxide nanoparticles. Pol. J. Environ. Stud. 25, 557, 2016.

10. PALIULIS D. Removal of formaldehyde from synthetic wastewater using natural and modified zeolites. Pol. J. Environ. Stud. 25, 251, 2016. 
11. IQBAL M., ABBAS M., ARSHAD M., HUSSAIN T., KHAN A., MASOOD N., TAHIR M.A., HUSSAIN S.M., BOKHARI T.H., KHERA R.A. Gamma Radiation Treatment for Reducing Cytotoxicity and Mutagenicity in Industrial Wastewater. Pol. J. Environ. Stud. 24, 2745, 2015.

12. FAKHRI A. Investigation of mercury (II) adsorption from aqueous solution onto copper oxide nanoparticles: Optimization using response surface methodology.Proces. Safe. Environ. Protect. 93, 1, 2015.

13. FAKHRI A., BEHROUZ S. Comparison studies of adsorption properties of $\mathrm{MgO}$ nanoparticles and $\mathrm{ZnO}-$ MgOnanocomposites for linezolid antibiotic removal from aqueous solution using response surface methodology. Procs. Saf. Environ. Protect. 94, 37, 2015.

14. GHANEM K.M., Al-GARNI S.M., Al-ZAHRANI M.A. Bioremediation of diesel fuel by fungal consortium using statistical experimental designs. Pol. J. Environ. Stud. 25, 2016.

15. FAKHRI A. Assessment of Ethidium bromide and Ethidiummonoazide bromide removal from aqueous matrices by adsorption on cupric oxide nanoparticles. Ecotoxicol. Environ. Saf. 104, 386, 2014.

16. FAKHRI A., BEHROUZ S. Improved uptake of steroid hormone from aqueous solution using $\gamma-\mathrm{Fe}_{2} \mathrm{O}_{3} /$ NiOnanocomposites. J. Ind. Eng. Chem. 26, 61, 2015.

17. FAKHRI A., NAJI M. Degradation photocatalysis of tetrodotoxin as a poison by gold doped $\mathrm{PdO}$ nanoparticles supported on reduced graphene oxide nanocomposites and evaluation of its antibacterial activity.J.Photochem. Photobio. B: Biol. 167, 58. 2017.

18. FAKHRI A., BEHROUZ S. Synthesis, photocatalytic and antimicrobial properties of $\mathrm{SnO}_{2}, \mathrm{SnS}_{2}$ and $\mathrm{SnO}_{2} /$ $\mathrm{SnS}_{2}$ nanostructure. J.Photochem. Photobio. B: Biol. 149, 45, 2015.

19. SHAO M., SHAO J.Z., LI P., DING Y. Reaction of a heterobifunctional reactive dye (ci reactive red 195) with amino groups and phenol groups. Adv. Mater. Res. Trans Tech. 132, 2012.

20. PATEL P.K., SANDIP P.K., PARESH P.S., KESHAV C.P., Synthesis of monoazo reactive dyes and their dyeing performance on various fibers.Int. J. Recent Sci. Res.6, 646, 2015.

21. BRITAIN G. In the Methods of test for colour fastness of textiles and leather, $5^{\text {th }}$ ed., Bradford, SDC. 1990.

22. KOUSHA M., DANESHVAR E., DOPEIKAR H., TAGHAVI D., BHATNAGAR A. Box-Behnken design optimization of Acid Black 1 dye biosorption by different brown macroalgae. J. Chem. Eng. 179, 158, 2012.

23. HAMSAVENI D.R., PRAPULLA S.G., DIVAKAR S. Response surface methodological approach for the synthesis of isobutyl isobutyrate. Proces.Biochem. 36, 1103, 2001.

24. ANDERSON M.J., WHITCOMB P.J. In the RSM Simplified: Optimizing processes using response surface methods for design of experiments, Productivity press, New York. 2005.

25. FARHA S.A., GAMAL A.M., SHALLAM H.B., MAHMOUD G.E.A., ISMAIL L.F. M.J. Am. Sci., 6, 109, 2010.

26. SAEED Q., BHATTI I., ZUBER M., NOSHEEN S., ZIA M. and ABBAS M. Study of application of mono azo reactive dyes on cotton by exhaust method and printing properties. Int. J. Basic Appl. Sci. 12, 191, 2012.

27. SINGLA J., JEET S.S., ROSE N.M.Standardization of dyeing variables of reactive dye for tie and dye on cotton. GlobalRes. Anal. 1, 77, 2012.
28. BABARINDE A., OGUNDIPE K., SANGOSANYA K.T., AKINTOLA B.D., ELIZABETH HASSAN A.-O. Comparative study on the biosorption of $\mathrm{Pb}(\mathrm{II}), \mathrm{Cd}(\mathrm{II})$ and Zn(II) using Lemon grass (Cymbopogoncitratus): kinetics, isotherms and thermodynamics. Chem. Int. 2, 89, 2016.

29. BABARINDE A., ONYIAOCHA G.O. Equilibrium sorption of divalent metal ions onto groundnut (Arachishypogaea) shell: kinetics, isotherm and thermodynamics. Chem. Int. 2, 37, 2016.

30. ELVIA R., CAHYANA A.H., WIBOWO W. Catalytic acetylation of (+)-cedrol with heterogeneous catalyst $\mathrm{H}_{2} \mathrm{SO}_{4} / \mathrm{SiO}_{2}$ under solvent free conditions. Chem. Int. 1, 196, 2015.

31. GANGADHARA R., PRASAD N. Studies on optimization of transesterification of certain oils to produce biodiesel. Chem. Int. 2, 59, 2016.

32. IQBAL M., KHERA R.A. Adsorption of copper and lead in single and binary metal system onto Fumariaindica biomass. Chem. Int. 1, 157b, 2015.

33. JAFARINEJAD S. Control and treatment of sulfur compounds specially sulfur oxides (SOx) emissions from the petroleum industry: a review. Chem. Int. 2, 242, 2016.

34. JAMAL M.A., MUNEER M., IQBAL M. Photo-degradation of monoazo dye blue 13 using advanced oxidation process. Chem. Int. 1, 12, 2015.

35. MAJOLAGBE A.O., ADEYI A.A., OSIBANJO O. Vulnerability assessment of groundwater pollution in the vicinity of an active dumpsite (Olusosun), Lagos, Nigeria. Chem. Int. 2, 4, 2016.

36. NGOBIRI N., OKOROSAYE-ORUBITE K. Adsorption and corrosion inhibition characteristics of two medicinal molecules. Chem. Int. 3, 185, 2017.

37. PETER U.C., CHINEDU U. Model prediction for constant area, variable pressure drop in orifice plate characteristics in flow system. Chem. Int. 2, 80, 2016.

38. QURESHI K., AHMAD M., BHATTI I., IQBAL M., KHAN A. Cytotoxicity reduction of wastewater treated by advanced oxidation process. Chem. Int. 1, 53, 2015.

39. REMYA V., PATIL D., ABITHA V., RANE A.V., MISHRA R.K. Biobased materials for polyurethane dispersions. Chem. Int. 2, 158, 2016.

40. SAYED M. Efficient removal of phenol from aqueous solution by the pulsed high-voltage discharge process in the presence of $\mathrm{H}_{2} \mathrm{O}_{2}$. Chem. Int. 1, 81, 2015.

41. SHINDY H. Basics in colors, dyes and pigments chemistry: A review. Chem. Int. 2, 29, 2016.

42. SRIVASTAVA S., PRAJAPATI D. Kinetic and thermodynamic study of Os (VIII) catalysed oxidation of glycine by ferrate (VI) in alkaline medium. Chem. Int. 3, 30, 2017.

43. UKPAKA C. Development of model for bioremediation of crude oil using moringa extract. Chem. Int. 2, 19, 2016.

44. UKPAKA C. Predictive model on the effect of restrictor on transfer function parameters on pneumatic control system. Chem. Int. 2, 128, 2016.

45. UKPAKA C. Empirical model approach for the evaluation of $\mathrm{pH}$ and conductivity on pollutant diffusion in soil environment. Chem. Int. 2, 267, 2016.

46. UKPAKA C. BTX Degradation: The concept of microbial integration. Chem. Int. 3, 8, 2016.

47. ZHAO Y., WANG D., LI X., LIU Y. Determination of rutin, chlorogenic acid and quercetin in solidaginis by large volume sample stacking with polarity switching and acid barrage stacking. Chem. Int. 2, 121, 2016. 